\title{
Foundationalism and the Metaphysics of Practical Reasons
}

\section{Heath White}

Valparaiso University

Abstract: This paper argues that much contemporary thought about practical reasons is saddled with a questionable assumption. The assumption is that practical reasons owe their normative force to their metaphysical nature; or in other words, that "practical reason" is a metaphysical kind. This assumption is traced to an implicit foundationalism in views of practical reasons, which is itself a response to the threat of a form of skepticism: some practical reason must be able to stop a regress of practical reasons, on pain of there being no reasons for action at all. However, foundationalism about practical reasons, with its implicit commitment to practical reasons as a metaphysical kind, is not the only way to halt the skeptical threat. A contextualist alternative is sketched and some reasons are offered to prefer it.

Much ink has been spilled in the last thirty years or so debating the nature and source of our reasons to act-our practical reasons. A slow revolt against once-hegemonic instrumental theories has sparked new creativity among Humeans, Kantians, Aristotelians, and others. Virtually all of these views, however, share a common assumption, or perhaps better, a common picture of the form an answer must take. In this picture, our reasons to act are grounded in some kind of thing, which by its very nature provides us those reasons. More specifically, it is commonly assumed that there is some metaphysical kind appropriately labeled "practical reasons"- the debate, then, is a battle over which kind this is, and what its properties are. Do our reasons spring from contingent, subjective desire, or from the Form of the Good? Are they found in normatively loaded value, or ordinary natural fact? Is the source of our reasons subjective or objective? Agent-relative or agentneutral? Necessary or contingent? On this picture, practical thought begins with metaphysics. 
This underlying framework lies buried so deeply in the philosophical consciousness that it only rarely comes to light in discussion. Yet it is not a very sophisticated way to think about reasons, practical or otherwise. Moreover, it restricts the options for understanding practical reasons-and in my opinion, restricts them so as to rule out the truth.

The goal of this essay is to expose an embedded prejudice: the assumption, effectively, that practical reasons are a metaphysical kind. Perhaps exposure, and the provision of an attractive alternative, are enough to do the prejudice in. At the very least, though, they shift a certain onus of proof: the role of metaphysics in practical thinking needs reexamination.

\section{The Question}

The debate I hope to clarify deals, as I said, with the nature and source of our reasons for acting. It's not exactly clear what questions are being asked, however, and unfortunately, few philosophers have made any attempt at clarification. To get some handle on the discussion, I'll point out ways in which competing claims get phrased. Frequently, claims are put in terms of sources of reasons (emphases added in all quotes):

On Internalist theories, the source of all reasons is something that is not itself normative.... On Externalist theories, the source of any reason is something normative.'

To begin with, such states are not, as desires are supposed to be, original sources of reasons. ${ }^{2}$

Other times, claims are made about what grounds or provides or generates a reason for acting, or what reasons are based on:

The question underlying this debate is whether moral obligations that take a categorical form can provide good reasons for action. ${ }^{3}$ Suppose, for example, that the reason generated by a desire is the fact that one has the desire ${ }^{4}$ 
On one common view, the only justifications for agents' actions are grounded in their wants and desires. ${ }^{5}$

The hallmark of what are now called Humean theories of practical rationality is the assertion that "reason is ... the slave of the passions"-that reasons are hased, ultimately, on subjective, contingent, conative states of the agent. ${ }^{6}$

We could multiply examples like these indefinitely.

One of the few authors to actually frame the relevant question explicitly, and make some attempt to clarify it, is Jonathan Dancy. When he does manage to shed light on it to some extent, the metaphysical twist to the question becomes plain:

This distinction [between desire-based and value-based normative reasons] is much harder to characterize, since there has been no authoritative discussion of it. The desire-based view seems to be that all normative reasons are 'provided' by desires of the agent, while the value-based view is that some reasons, at least, are provided by ('grounded in') values such as the value of achievement, of pleasure, of friendship, or whatever. As such, these two views seem to be about the metaphysical ground for a reason-about what creates or generates it.

What is a "source" of reasons? A "ground"? What does it mean to "provide" a reason? The very obscurity of these questions, so infrequently addressed, is a datum. A concept which everyone feels comfortable invoking, but which no one can explain, is basic to a way of looking at a subject. At issue, fundamentally, is the question of why we have the reasons for action that we do. When Dancy tracks down the central issue of debate, he reveals the underlying assumption: reasons for action derive from a metaphysical root. Later in the essay I will suggest a different way of framing the debate, and a diagnosis of why it tends to get framed in the terms it does.

Let me quickly canvass the most common ways of offering an answer to this question. For a long time, the dominant view was that subjective attitudes grounded or provided our reasons to act. 
(From now on I'll refer to these attitudes as 'desires', though that stretches the term.) The view is often called Humean, though it's doubtful Hume ever held such a position. ${ }^{8}$ The view is quite clear in Hobbes, however:

But whatsoever is the object of any man's appetite or desire that it is which he for his part calleth good; and the object of his hate and aversion, evil; ... For these words of good, evil ... are ever used with relation to the person that useth them, there being nothing simply and absolutely so, nor any common rule of good and evil to be taken from the nature of the objects themselves?

\section{David Gauthier provides a contemporary rendition of it:}

Value, then, we take to be a measure of individual preferencesubjective because it is a measure of preference and relative because it is a measure of individual preference. What is good is good ultimately because it is preferred, and it is good from the standpoint of those and only those who prefer it. ${ }^{10}$

Because the view that our reasons to act are given by desires was (and is) widely, if perhaps incorrectly, associated with Hume, all views differing from this long-dominant one get lumped together as anti-Humean. Also, virtually all anti-Humeans invoke "value" as the thing the Humeans leave out. However, there are two quite different notions of value in play in the anti-Humean camp, 1 and hence two quite different anti-Humean answers to the question of what provides reasons to act.

The first, more traditional view holds that the world contains intrinsically normative entities or properties - values or goods. When we say that democracy is a good form of government, or that friendship is a value, we speak the literal, uncomplicated truth. I shall, with only partial justice, call this broad position Aristotelianism, though varieties of it range from Plato's semimysticism to Aristotle's functional approach to the sophisticated contemporary versions of David Brink and John McDowell. The common mark of these theories is to suppose that the intrinsically normative entities or properties - the goodness of democracy, or 
the value of friendship-give us reasons to act; for instance, to promote democracy around the world, or to maintain our friendships.

The second anti-Humean construal of value, instead of seeking to ground reasons for action in value, defines value in terms of reasons for action. Thomas Scanlon helpfully dubs this more recent view the "buck-passing" view of value. On this account, something has value (is good) if it has some feature which gives us a reason to take action..$^{12}$ The reason, in this case, is some natural fact: e.g. that she is stranded on the side of the road gives me a reason to assist her; that he is engaged in criminal activity gives me a reason to report him to the police. Scanlon, who endorses this position, calls it the "buck-passing" view because the concept of value does no independent work; value just "passes the buck" to the feature which gives us the reason for action. Calling something valuable is just a way of saying that it has a certain kind of reason-giving feature.

Each of these candidate answers identifies a metaphysical kind as the ground of practical reasons. For the Humeans, the kind is psychological states of desire. These and only these provide reasons to act. For the Aristotelians, value, goodness, or some other normative property provides the reasons. For the buck-passers, the metaphysical type that provides practical reasons is simply the natural world itself. ${ }^{13}$

\section{Recasting the Question}

Now that we understand something of the possible answers to the debate over the nature and source of our practical reasons, I'd like to revisit the debate itself. As near as we could tell, it hinged on a dispute over, in Dancy's words, "the metaphysical ground for a reason ... what creates or generates it." This language of fertility-"creating" or "generating" reasons-is none too clear, and so long as we rest content with it, the exact question we are trying to answer remains mired in obscurity. I believe the question can be made precise, but only by dropping the metaphysical baggage currently in tow. That is, when we have a clear grasp of 
what is being asked, when we ask about the nature and source of our practical reasons, we will not need to have recourse to a "metaphysical ground."

The first point of clarification concerns the relation between what provides a reason, and the reason it provides. Take a simple example. Suppose my grandmother is coming to stay and I have promised my parents I'll keep her happy while she visits. We might say that what gives me a reason to keep my grandmother happy while she stays with me is that I promised my parents I would. Now, according to this example, "that I promised to do it" gives me, or provides, or grounds, or is the source of, a reason to keep my grandmother happy. But what reason does it give me? The only way to describe the reason I have for keeping my grandmother happy seems to be, that I promised to do it.

So the locutions, 'gives a reason' or 'grounds a reason' or 'provides a reason,' are misleading. It is not as if one thing provides a reason, and a second thing is the reason. Rather, the grounds or sources or providers of reasons just are reasons, albeit of a certain privileged kind. ${ }^{14}$

When we go on to ask which sort of reasons they are, and what privilege they enjoy, we move to a second point of clarification. The special status accorded these grounding reasons comes out when we concentrate on the role that they play in practical reasoning.

Practical reasoning occurs in at least two contexts, justificatory and deliberative. Whenever we try to justify a past or future intended action, we cite reasons for it. These reasons will be inferentially related to the action; they will be premises in an argument which concludes in the action to be justified. For instance, when asked why I brought my grandmother a cup of tea, I may reply that I wanted to keep my grandmother happy and, since she is fond of tea, I could do that by bringing her some tea. The argument corresponding to this reasoning, of course, is

Let me keep my grandmother happy.

If I bring her some tea, I will keep my grandmother happy.

So, I'll bring my grandmother some tea. 
The other context is deliberation, or more generally trying to figure out what to do. Perhaps I want to keep my grandmother happy; how can I do this? Here, naturally, the same argument presents itself.

Corresponding to these two contexts in which practical reasoning surfaces are two sorts of doubt or worry. In the justificatory context, we might wonder whether my desire to keep my grandmother happy should count as a justification, that is, as a good reason for doing anything at all. Are we quite sure that this desire was worth acting on?

Likewise, in the deliberative context, I might wonder whether my desire to keep my grandmother happy, and the fact that bringing her some tea would keep her happy, are really good reasons for doing anything. After all, is it right to so supinely cater to my grandmother's every whim? Again, is my desire a worthy one?

Answering these parallel questions puts us on a regress. Whatever reasons I offer for wanting to keep my grandmother happy, similar questions may arise about those reasons. If we cannot halt this regress somehow, we are in for skepticism about practical reasons: it will seem undeniable that nothing, in fact, genuinely gives us a reason to act. To stop the regress, what we need is a real practical reason. Perhaps, in the present case, the regress-stopper could be supplied by, "I promised my parents I'd kecp my grandmother happy" as a reason for wanting to pleasc my grandmother. Just here is the privilege accorded grounding reasons-they halt regresses of practical argument.

The special role of these grounding reasons is a rolc in practical reasoning. What practical reasons are for is for serving as premises in practical arguments and practical reasoning, in the justificatory context, the deliberative context, or some other context where argument or reasoning is appropriate. ${ }^{15}$ What the special kind of practical reasons are for-the kind we sometimes misleadingly say "give" or "provide" us reasons to act—is for stopping a regress of such arguments. They are reasons for which no further reasons are needed.

Now, it isn't obvious that what is meant by "a source of practical reasons" is "a regress-stopper," so we should pause and 
ask whether what we have found is what we were looking for. The metaphors of "source" and "ground" bespeak an indistinct grasp of the issue, I claim, and are rendered literal when we take them to describe regress-stoppers for practical arguments. The picture is this: when an offered reason needs a further reason to back it up, it's not a font of normative force, as it were, but a channel. Just because it needs backing up by a further reason, the normative force of the offered reason draws from some other source, namely, the back-up reason, or whatever its source of normative force is. Whereas when a reason doesn't need backing up, it generates, or provides, or grounds, or gives us, normative force all by itself. Thus the function of halting regresses of practical argument is pictured with the images of source and ground.

Once we have identified a practical reason of whatever sort, there is of course no harm in doing descriptive metaphysics. Is it a desire, or a value, or a proposition, or what?-this is perfectly innocuous and reasonable question. Descriptive metaphysics hasn't been the goal of all those philosophers who have debated the source of practical reasons, however. They have generally sought to identify a certain privileged class of reasons for acting, and to understand what that privilege consists in. We have done that without (yet) invoking any metaphysical categories. The privilege is constituted by a certain function-a role within practical reasoning-rather than by the nature of what has the function. Of course, a reason might come to have this function only in virtue of its nature; that, however, would be a substantive thesis. It is, in fact, the substantive-and I believe, mistaken-thesis shared by nearly all current answers to the question about the nature and source of our practical reasons.

\section{Foundationalism about Practical Reasons}

My contention is that the three theories of what gives us our practical reasons are competing forms of foundationalism about practical reasons. To understand this claim and its implications, I'll need to explain what foundationalism about practical reasons amounts to. 
A foundation is a justifier which itself needs no justificationa reason (for believing, or acting, or anything else) which does not itself require reasons. If we understand the debate over the nature and source of our reasons for acting to be a debate about what constitutes a certain privilcged class of reasons for acting - namely, the regress-stoppers, the reasons which don't need further reasons-then it becomes clear that what we seek, in pursuing this debate, are the foundations for practical reasoning.

Foundationalism, as traditionally conceived, goes beyond the mere belief in foundations - the belief, essentially, that regresses of argument must come to an end somewhere. Foundationalism includes the idea that, because we need something to stop the regress of reasons, there must be some kind of thing that does this. Or in other words, foundationalism incorporates the substantive thesis mentioned at the end of the last section: that whatever performs the function of halting regresses of argument does so in virtue of its (metaphysical) nature. In epistemology, the most popular candidate has been (some variation on) appearances. In the field of practical reason, there are three candidates current, embodied in the three theories of what gives us our practical reasons, summarized above: desires, values, and facts.

Consider again the case where I have brought my grandmother some tea because I wanted to keep her happy, and now we wonder whether this was a good idea. Those Humeans who take any ultimate desire to give reasons to act will say that, if keeping my grandmother happy is an ultimate desire of mine, then it doesn't need defense-it stops the regress of reasons by itself. If, alternatively, my desire to keep my grandmother happy is not ultimate, but can be traced back by suitable chains of instrumental reasoning to ultimate desires I do have, then those desires stop the regress. Those ultimate desires are thus what give agents practical reasons, according to the Humean.

If one believes that values give agents their normative practical reasons, however, one tells a somewhat different story about what stops the regress of reasons. If the object of my desire-namely, keeping my grandmother happy - is a value, or an instance of one, then, on this theory, the regress is stopped: I don't have to give 
further reasons for wanting to keep my grandmother happy. It's valuable to do so, and there's an end to it. Or if my desire to keep my grandmother happy can be shown to subserve a value, as a means to it, for instance, then again, the regress of reasons is stopped once we invoke a value.

Those who think that practical reasons are facts will probably think that the first, Humean position makes a mockery of serious practical reasoning, and they'll think the appeal to values questionbegging, metaphysically dubious, or simply misleading. What gives me a reason to please her will be some fact, like "she's my grandmother" or "I promised to." Once we cite a fact of this sort, this line goes, the regress is halted. Hence facts are the practical reasons we were seeking.

Each of the answers to the question of what gives us reason to act is, in reality, a foundationalist position about practical reasons. Each posits some kind or type of thing which, when invoked as a reason, stops anyone from asking for yet another reason. But this sort of answer - the felt need for a kind or type of thing to stop the regress of reasons-results in no small part from the way one frames the original debate. Remember Dancy's original formulation: "these two views seem to be about the metaphysical ground for a reason-about what creates or generates it." When we frame the issue in metaphysical terms like this, it looks like only a metaphysical answer will provide the solution. Whatever has this mysterious power of grounding reasons must do so in virtue of its nature. Hence we look for a kind of thing which, in virtue of its intrinsic properties, will do what we want-namely, end a regress of reasons for a practical conclusion.

At least to philosophers of a certain vaguely pragmatic cast, foundationalism about practical reasons results in bad methodology. We find ourselves hunting for a priori arguments, rather than looking to the actual practice of practical reasoning to understand how various considerations come to have the normative authority for us that they do. For philosophers of this persuasion, metaphysics feels like the wrong place to begin practical thought, but given foundationalism, it's the only place to begin.

Foundationalism has another drawback. The foundationalist 
assumption - that the role of regress-stopper is necessarily played by some kind of thing-restricts the options for understanding practical reasons. The dispute between advocates of fact-, value-, and desire-based reasons is predestined, in the minds of the disputants, to one of three outcomes. A priori, the foundationalist is certain that only a kind of thing, a metaphysical type, will ground reasons in the way she needs. Yet this attitude forecloses all sorts of otherwise attractive possibilities, which remain invisible as long as the assumption is in place.

As I said in the introduction, this assumption lies deep, so deep that it rarely gets articulated. It has taken some work to bring it out into the open. It embodies what Wittgenstein would call a "picture"-a way of looking at a subject which channels thought along certain paths so effortlessly that one doesn't even realize those paths aren't necessities. One good way to break the grip of such a picture is to provide an attractive alternative-to demonstrate just how optional, and perhaps crude, the picture is. That is my goal in the rest of the essay.

\section{Non-foundationalism about Practical Reasons}

The debate over the nature and source of our practical reasons isn't pointless. We need certain privileged practical reasons; we need something to stop regresses of argument: to end the quest for yet further justification and yet deeper reasons for action.

But this is all we need. The characteristic foundationalist assumption, that the members of the privileged class of reasons stop regresses in virtue of their nature, is an extra, and ungrounded, requirement. Noticing this assumption allows us to try rejecting it, and paves the way for a non-foundationalism about practical reasons.

Consider this possibility: it might be that a particular fact or value or attitude (we won't yet settle on which) will halt a regress of argument in a particular case, not due to some built-in quality but instead, due to the force of surrounding circumstances. That is, 'being a regress-stopper' might be a relational property-one which a fact or attitude has in virtue of its relations with various 
other clements of the situation-rather than an intrinsic property, one which it has essentially, or as part of its nature.

Call the view that regress-stopping is a relational property, contextualism. ${ }^{16} \mathrm{~A}$ contextualist thinks that what stops a regress of argument, in a particular case, depends a great deal on the circumstances-on the contexts in which particular cases of practical reasoning go forward. In a given case, a contextualist will say, a premise may not be subject to challenge. But in some other case, it probably will. Whether or not a premise is subject to challenge, and hence whether a threat of regress is real, depends not on the intrinsic qualities of the premises but on the situations in which particular cases of reasoning are going forward. In principle, any premise can be challenged-in some context. And in principle, any premise can be immune from challenge-in some context. What can be taken for granted at one point may be contentious at another, and vice versa.

The contextualist approach mirrors our actual practice of giving and asking for practical reasons much better than the foundationalist approach. In ordinary discourse, any of facts, values, or attitudes can provide reasons to act for which no further reasons need be provided. It's certainly true that, at times, we feel free to justify our actions simply by citing a desire we have. Asked, "Why did you get up from the couch?" a perfectly good answer is, "I wanted to get some ice cream." In ordinary circumstances at any rate, no one will ask for further reasons. We also invoke values, though rarely label them as such: if someone asks me why I'm stuffing envelopes, and I answer, "To protect the environment," the value attached to the environment goes without saying. It's also true that we often stop at facts. "Why did you stop at the intersection?" is adequately answered by, "There was a stop sign there." Generally speaking, no one will go on to ask what inferential connection we discern between the presence of stop signs and stopping one's car.

In fact, a philosophically informed look at our reasoning supports this pluralism about practical reasons. The clue lies in the formal structure of practical reasoning, but I'll approach the issue by analyzing formal arguments in the theoretical realm. 
Among the several promising ideas which have emerged in recent years from the philosophical tradition influenced by Wilfrid Sellars, especially through the influence of Robert Brandom's 1994 book Making It Explicit, ${ }^{17}$ is an innovative philosophy of logic. On this view, the vocabulary of formal logic is used to make explicit the inferential proprieties already present in informal reasoning. Here, I'll concentrate on the analysis of conditionals.

For instance, when reasoning informally, we often say things like, "The cherry trees are blooming, so spring is here." To make this informal argument deductively valid, however, we have to add a conditional premise. Formally rendered, the argument is

The cherry trees are blooming.

If the cherry trees are blooming, then spring is here.

Therefore, spring is here.

It's something of a question what exactly the added premise adds. After all, no one who accepts the informal version of the argument would dispute the claim, "If the cherry trees are blooming, then spring is here"-they show that they believe this simply by accepting the informal argument. For a Sellarsian, this fact provides the clue to understanding conditionals in general. An if-then statement allows one to make explicit in language a pattern of inference; the if-then statement will be accepted (considered true) just in case the pattern of inference is accepted. Whereas, without this bit of logical vocabulary, one can only do something - accept or reject an informal inference-with it one can say what one does-one can put the inferential pattern into language. Thus the 'if...then...' locution is an expressive device; it allows one to talk about the underlying practice of informal inference.

Those, in brief, are the thoughts behind what I'll call, following Brandom, an expressive theory of conditionals. I will not argue further for this theory, though I do think it is correct. Instead, I'll show how it helps us demonstrate that we treat all sorts of metaphysical types as practical reasons. ${ }^{18}$

The expressive theory of conditionals enables us to draw a distinction among types of practical reasoning. We can take any 
bit of practical reasoning and display it as an argument. One bit we have seen so far is,

I promised I would keep my grandmother happy.

If I promised to keep my grandmother happy, I'll do it.

So, I'll keep my grandmother happy.

Another bit of practical reasoning we have already run across is,

Let me keep my grandmother happy.

If I bring her some tea, I will keep my grandmother happy.

So, I'll bring my grandmother some tea.

The expressive theory tells us, in each of these cases, that the conditional premise expresses the informal propriety of an inference from its antecedent to its consequent, serving only an explicitating role, and so does not add to the force of the argument. Since these arguments are equally forceful without the conditional premise, we could rephrase them as follows:

I promised I would keep my grandmother happy.

So, I'll keep my grandmother happy.

Let me keep my grandmother happy.

So, I'll bring my grandmother some tea.

Now the difference in the arguments, and hence in the reasoning they reflect, should be evident. The premise of the second practical argument expresses a desire, or more generally, an attitude, while the premise of the first expresses an (ostensible) fact.

So the expressive theory of conditionals reveals at least two different kinds of practical reasoning. Sometimes we take the facts of the case to provide reasons for action, as in the first case; other times, as in the second case, we take our attitudes to provide reasons for action. Taking values to provide practical reasons collapses 
into one of the other two cases: realists will think of value as a special kind of fact, while those with more expressivist tendencies ${ }^{19}$ will treat claims about value as expressions of attitude. The pluralism of our actual practice raises the possibility that "the source of our reasons" is pluralistic too: that both facts and attitudes, in suitable cases, can stop regresses of practical argument.

Any foundationalist, confronted with this diversity of reallife regress-stoppers, will instinctively look for a way to reduce one to another. Certain things, she will say, must be assumed, or implied, or tacit, in one case or the other, and those are the real reasons for action. I suggest that this "must" is one of those philosophical "musts" Wittgenstein warns us about: not the result of investigation into the phenomena, but of a preconccived requirement imposed by a philosophical picture. We know why a foundationalist wants to say these things: because her picture is one of a metaphysical type, the font of normative force. The very possibility of contextualism, however, removes the necessity of that picture. The fact that ordinary practice looks like it favors the contextualist is reason to abandon the foundationalist picture of practical reasons, not to postulate hidden elements in ordinary practice.

What sort of change in perspective would contextualism result in? If being a regress-stopper is a relational property as the contextualist claims, then in principle anyway, anything that can serve as a premise in practical reasoning can stop some regress of practical argument. There will be as many metaphysical kinds of regress-stopper as there are kinds of premise-facts, values, and attitudes can each, in different contexts, perform this function. It all depends on the circumstances of particular bits of practical reasoning.

It follows that no intrinsic quality will mark out all and only the regress-stoppers. The debate about the nature and source of our practical reasons has operated under a misapprehension: that the function of halting regresses of argument was guaranteed by the nature of a special type of practical reason; hence that there was some general theory of these privileged practical reasons to be had. But if the contextualist is right, the privilege associated 
with these practical reasons is not due to any nature. The quest for such a theory would rest on a false presupposition-that there is such a metaphysical type as a "source of reasons to act."

Of course, we could still ask about the metaphysical classification of our grounding reasons. The point of these questions is changed, however: if we don't assume, with the foundationalist, that practical thought begins in metaphysics, these questions are much less interesting. They may classify our practical reasons, but they won't hold the secret to their importance.

We can also legitimately continue to hear and offer a priori arguments that such-and-such a kind of thing must, or cannot, be a regress-stopping practical reason. But the point of these arguments changes also. We will not think, with the foundationalist, that just because debates are inconclusive, some mystery remains about the sources of our practical reasons. We can stick closely to ordinary practice, and suppose that the sources of our practical reasons are pluralistic until proven otherwise. If some sound argument can show that one type of practical premise is barred from ever being a stopping point in practical reasoning, so be it. If, at the end of the day, there is only one candidate for the post of regress-stopper left standing, so be it. But those are conclusions far down the road, not a priori convictions we start with.

\section{Conclusion}

My aim is to dislodge a prejudice-at the very least, to expose the foundationalist assumption as an assumption, so that we can intelligently evaluate whether or not to continue thinking under its shadow. The central bone of contention in the debate over the nature and source of our practical reasons revolves around what can be relied upon to halt regresses of practical argument. Taking a position in this debate does not essentially require delving into the metaphysics of reasons. The very possibility of a nonfoundationalist way of understanding the sources of our practical reasons removes the temptation to think that there must be a general theory of the source of practical reasons. This in turn means that the foundationalist has to defend his substantive thesis-that the 
function of stopping regresses depends on the nature of the regressstoppers-as never before. If (as I suspect) that assumption does not prove very defensible, contextualism provides a satisfying theoretical alternative. In this small corner of debate, it may turn out as Wittgenstein desired: we can stop doing that kind of philosophy when we want to.

\section{Notes}

'Derek Parfit, 'Reasons and Motivation', Proceedings of the Aristotelian Society, Supplementary Volume 77 (1997), p. 129.

${ }^{2}$ T. M. Scanlon, What We Owe to Each Other (Cambridge, MA: Harvard University Press, 1998) p. 45.

${ }^{3}$ Joseph Heath, 'Foundationalism and Practical Reason', Mind 106 (1997), p. 453.

${ }^{4}$ J. David Velleman, 'The Guise of the Good', Nous 26 (1992), p. 10.

' Paul Hurley, 'A Kantian Rationale for Desire-Based Justification', Philosopher's Imprint 1 (2001), p.1.

${ }^{6}$ Donald C. Hubin, 'What's Special about Humeanism', Nous 33 (1999), p. 30.

${ }^{7}$ Jonathan Dancy, Practical Reality (Oxford: Oxford University Press, 2000), p. 17. Emphasis added.

${ }^{8}$ For doubts about Hume's adherence to this view, see Jean Hampton, 'Does Hume Have an Instrumental Conception of Practical Reason?', Hume Studies 21 (1995).

${ }^{9}$ Thomas Hobbes, Leviathan, ed. Edwin Curley. (Indianapolis: Hackett, 1994), p. 29.

${ }^{10}$ David Gauthier, Morals by Agreement (Oxford: Clarendon Press, 1986), p. 59.

"At least. For discussion of a number of variations on the concept of value, see Jonathan Dancy, 'Should We Pass the Buck?' in A. O'Hear (ed) Philosophy, the Good, the True, and the Beautiful, Royal Institute of Philosophy Supplement 47 (Cambridge: Cambridge University Press, 2000).

${ }^{12}$ See Scanlon (1998) ch. 2. In full-blown versions of this theory, more than action can be indicated: there might also be reasons for choosing, protecting, preserving, admiring, respecting, and so on. We'II confine ourselves to the narrower topic of reasons for action.

${ }^{13}$ It might be thought that there is a third class of anti-Humean views, namely those built around the notion of authority. I have in mind Kantians, 
social contract theorists, and divine command theorists, for whom the ultimate authority for creating practical reasons is the autonomous rational agent, the society, or God, respectively. I tend to think of these views as variations on buck-passing, where the relevant natural fact is of the form, " $X$ said so." $X$ 's authority just consists in the fact that " $X$ said so" is an ultimate reason for action. However, that can only be a first approximation to an adequate treatment of these influential traditions, and for reasons of space they will not be further treated here.

${ }^{14} \mathrm{~A}$ slight variation on these phrases is not so misleading. Sometimes we say things like, 'The fact that you promised gives you reason [not $a$ reason] to pick him up at the airport.' Here, presumably, 'reason' names some kind of normative force, so to speak, and the reason is what generates the normative force, namely the fact that you promised.

${ }^{15}$ For instance, the hypothetical context: 'Suppose your grandmother liked tea...'

${ }^{16}$ I have taken the term 'contextualism' from contemporary epistemology. There it can mean a number of different things. The least sophisticated version of contextualism is one that thinks the standards of evidence vary from context to context on a linear scale, from 'low' to 'high'. This ignores the multi-dimensional nature of evidence; what can be taken for granted, or needs justifying, in one context may not in another, but there is no well-ordering of things that can be taken for granted. I have in mind this more sophisticated meaning of contextualism, applied to the practical realm.

${ }^{17}$ Robert Brandom, Making It Explicit (Cambridge, MA: Harvard University Press, 1994).

${ }^{18}$ The foregoing is largely an exposition of Brandom (1994) pp. $97-$ 116. What follows is inspired by Brandom's views, though different from the positions he endorses.

${ }^{19}$ Here I mean expressivism about normative or evaluative discourse, for instance as defended by, for instance, Gibbard and Blackburn. (Simon Blackburn, Ruling Passions: A Theory of Practical Reason [Oxford: Clarendon Press, 1998). Allan Gibbard, Wise Choices, Apt Feelings (Cambridge, MA: Harvard University Press, 1990).] Not to be confused with the expressive theory of logic presented above. 